\title{
Obsessional disorder and neurological illness
}

\author{
LINTON GRIMSHA W' \\ From the University Department of Psychiatry, Manchester Royal Infirmary
}

Obsessions and compulsions are mental experiences with a compelling quality which persistently intrude into consciousness. Although recognized by the patient as an abnormal and irrational product of his own mind, and resisted by him, he is incapable of expelling them. They may take the form of thoughts, images, fears, urges, desires, or acts. An obsessional illness is one where such symptoms dominate the clinical picture and are not associated with any underlying psychotic process or phase.

Since the end of the last century, attempts have been made to understand obsessional disorder in neurological terms. Gadelius (1896), in Sweden, considered that obsessions were exaggerations of normal mental functioning and compared them with suggestibility and contrast thinking. He believed that every idea had a counter-idea, like an echo. Postulating an organic brain lesion, Gadelius suggested that the former had a cortical, the latter a subcortical, origin. Where there was a constitutional tendency for cortical weakness, subcortical centres were released from higher control and obsessional phenomena appeared clinically.

An organic explanation for obsessional symptoms was subsequently advanced by a number of writers, particularly Goldstein (1924), Wexberg (1929 and 1938), and Schilder (1938). This theory gained ground from the work of Mayer-Gross and Steiner in 1921. They found symptoms similar to obsessional in postencephalitic Parkinsonism. A number of other investigators later confirmed this finding (Ewald, 1924; Falkiewicz and Rothfeld, 1925; Scharfetter, 1926; Stern, 1927; Skalweit, 1928).

The present study represents part of a clinical, social, and prognostic inquiry into obsessional disorder. In investigating the medical history of patients suffering from such an illness, an attempt was made to discover the incidence of previous neurological disorder. This, it was felt, might throw some light on the possible connexion between obsessional symptoms and disease of the central nervous system.

\section{MATERIAL AND METHODS}

The material for the investigation was drawn entirely from patients attending the University Department of

${ }^{1}$ Present address: Bury General Hospital, Lancashire
Psychiatry of the Manchester Royal Infirmary between the years 1945 and 1959. The patients fulfilled the criteria for obsessional illness given above. One hundred and seven such patients had attended the department and their records were scrutinized. A detailed medical history was available in 103 cases.

A control group of patients with non-obsessional neuroses was set up, matched for age and sex, drawn at random from the same locality, and having attended the psychiatric clinic over the same period of time. They comprised 62 cases of anxiety state and 45 cases of hysteria. Relevant information was available in 105 cases. The differences regarding previous neurological illness in the two groups could then be subjected to the $\chi^{2}$ test of statistical significance.

Both groups of patients had been investigated with the same degree of thoroughness. The only difference between them was that, unlike many of the obsessional patients, the control series was not examined personally. Personal questioning of the obsessional patients did not reveal any further case of unrecorded neurological illness, but caused some cases to be discarded as doubtful. It seems reasonable to conclude that in the control series, which was written up to a similar standard, lack of personal examination would produce a bias, if any, in the right direction, for certain cases which might have been excluded as unreliable could not be assessed.

\section{RESULTS}

These are set out in Table I.

On the evidence available, 28 obsessional patients $(27 \cdot 2 \%)$ had suffered from one or more forms of neurological disorder. The clinical records of the patients concerned have been examined in detail in an attempt to assess the reliability of their information.

Three patients reported encephalitis, and two of these had had encephalitis lethargica. One patient said she had contracted it at the age of 3 during the great pandemic, and stated that her father had died from it. The other, also a woman, had developed it and recovered just before the onset of her compulsive symptoms. This woman was examined personally; there seemed little doubt from her clinical description and the statements of the physician attending her at the time that the diagnosis was correct. The third was a case of polio-encephalitis. The illness had occurred at the age of 11 years. Both 
TABLE 1

PREVIOUS NEUROLOGICAL DISORDER

\begin{tabular}{lll} 
Illness & $\begin{array}{l}\text { No. of Obsessional } \\
\text { Patients }\end{array}$ & $\begin{array}{l}\text { No. of Non- } \\
\text { obsessional Controls }\end{array}$ \\
\hline
\end{tabular}

Sydenham's chorea
Convulsions in infancy
Diphtheria
Encephalitis
Meningitis
Epilepsy
Herpes zoster
von Recklinghausen's disease
Heat stroke
Subacute combined degeneration
of the cord
Bell's palsy
Anterior poliomyelitis
Eclampsia with fits
Birth injury with hemiplegia
Pòrencephalic cyst and atrophy
Beri-beri

2

1

1

1

1

parents were questioned closely as well as the patient; little doubt remained of its factuality.

Two patients reported meningitis in childhood. No confirmatory data were available in one case; the other was described as a nearly fatal illness at the age of 3 which the patient was told was meningitis.

One patient had suffered from poliomyelitis and this was confirmed by neurological examination at the time of consultation. Thus six patients $(5.8 \%)$ gave a previous history of serious infectious illness of the central nervous system.

Eight patients $(7.8 \%)$ gave a history of convulsive disorders. Five patients reported convulsions in infancy; it was impossible to verify this information. They had not continued into later life. One woman had suffered from eclampsia with fits leading to a stillborn child. Two patients reported major epilepsy which was present at the time of consultation.

Five patients gave a history of diphtheria. It was difficult to assess the true state of affairs in these cases. No supporting data were available in the clinical records, let alone whether neurological complications were present. It is common experience in clinical practice to find patients calling any serious infection in the mouth and throat in childhood 'diphtheria'. No interpretation can be placed on this information and it is dismissed from the writer's calculations.

The information regarding chorea merits attention. Six cases $(5.8 \%)$ were reported. It was, in most cases, described as 'St. Vitus' dance'. Four patients gave details of an illness with uncontrollable jerking movements of the body, in three cases requiring bed rest in hospital. One case was doubtful and may have been, from the patient's description, a functional disorder of childhood, possibly a tic. The other was described in terms suggestive of chorea but prolonged bed rest was not reported.

In the control group of other neurotic conditions eight patients out of $105(7.6 \%)$ reported importane neurological illness. These comprised chorea (two cases), birth injury with hemiplegia (one case) porencephalic cyst and atrophy (one case), polioon myelitis (one case), convulsions (one case), menin gitis (one case), and beri-beri (one case). This is tor be compared with the obsessional series with 20 patients out of $103(19.4 \%)$ having had one or more important neurological illnesses, i.e., excluding. diphtheria (for reasons mentioned), herpes zoster, and Bell's palsy. The difference between the two groups is statistically significant at the $5 \%$ level of confidence with one degree of freedom, using Yates? correction $\left(\chi^{2}=5.24 \mathrm{P}=<0.05>0.02\right)$.

\section{DISCUSSION}

The association of epidemic encephalitis and com $\vec{\circ}$ pulsive disorder has already been mentioned in the introduction. Mayer-Gross and Steiner (1921) and Schilder (1938) have made important studies of this? connexion. Lewis (1946) states that encephalitis lethargica and other cerebral diseases may produce typical obsessional symptoms in persons free fron demonstrable tendencies in this direction.

Schilder (1938) came to the conclusion that orgatidi changes were important aetiological factors in two thirds of his obsessional cases and psychogenic factors in one-third. In the former group, organie signs-toxic change, tremors, impairment of ocuba convergence, hyperkinesis, or akinesis-were to 50 found in a third and a further third had symptoings suggestive of an organic background. In the majo of positive cases, he says, we do not deal with sequelae of epidemic encephalitis but with organic changes similar to those in encephalitis but of different origin. These may be constitutional or due to lesiong of foetal life, birth trauma, or to toxic and infectioug processes of unknown origin. Schilder tries to link psychoanalytic theory and clinical neurology. In? fantile experiences, he suggests, create a pattern which is expressed as compulsions on an organic basis. In obsessional disorder, the organic procesis: liberates motor impulses which reinforce sadistie attitudes to appear in the mind as compulsions? Wexberg (1929 and 1938) and Goldstein (1924) arg both quoted as seeing an organic nucleus in obsessional disorder. The part of the brain involved is that affected in Parkinson's disease, i.e., the corpus striatum.

A number of writers have commented on the relap tionship of obsessional illness and epilepsy (Fuchs? 1927; Jahrreiss, 1926). Aldren Turner (1907) and Crichton-Browne (1895) described obsessional states between fits. Garmany (1947) reported a case i⿱⿴囗十心 
which both epilepsy and obsessional symptoms were present. He speculated that a single pathology, of some extrapyramidal area, might be responsible for both manifestations.

The relationship of obsessional symptoms in patients with chorea has been investigated by Guttmann (1927) and by Creak and Guttmann (1935). Widepsread histological changes are found throughout the cortex, basal ganglia, and cerebellum in chorea (Greenfield, 1958).

Objections have been raised against a relationship between obsessional disorder and neurological illness. Pollitt (1958), for example, has discussed changes in personality and conduct which may follow any disease or injury of the brain, especially encephalitis. These usually take the form of emotional instability of a childish nature often with antisocial trends. The aberrant behaviour described as commonly following encephalitis is not found in people who fall ill with obsessional illness, neither during the illness nor before it. In fact, the obsessional character is the antithesis of the uncontrolled, antisocial, and wayward disposition of the post-encephalitic patient. Hall (1939) has described the mental accompaniments of epidemic encephalitis in children and states that when adult age is reached it is not accompanied by appropriate emotional maturation: 'They remain, more or less, childish'. As Pollitt (1958) remarks, this is hardly like the obsessional patient.

In relating the findings of this study to those of other writers, it is important to emphasize that the previous illnesses reported by patients could not, in the majority of cases, be verified either clinically or by hospital records. Inferences, therefore, can only be tentative. It would appear that about a fifth of patients had had previously some sort of important neurological disturbance, excluding trauma. It is difficult to say that in these patients organic cerebral changes had occurred. All the patients were subjected to neurological examination but none of Schilder's signs were recorded. On the other hand, they were not specifically looked for and may have been missed. Furthermore, it is doubtful whether the incidence of infantile seizures is higher than in the general population since febrile convulsions are not infrequent in childhood. Lennox (1947), for example, reported that seizures occur in about $5 \%$ of children under the age of 5 years.

Nevertheless, the incidence of neurological disease in the histories of the present series of obsessional patients cannot be overlooked, although it is lower than that found by Schilder. It is difficult to say with any certainty whether structural cerebral damage occurred and what part the illness played in the predisposition to the development of obsessional disorder later in life. Goldstein's view is called to mind that obsessional behaviour is a general disposition which can be released by the breakdown of higher performances. One may speculate that previous neurological disease isolates, as Goldstein would say, subcortical perseveratory activity from higher cortical centres. This might facilitate the emergence of compulsive phenomena when reinforced later in life by somatic or psychogenic precipitating factors. It would seem that further research is indicated in this field.

\section{SUMMARY}

The incidence of previous neurological illness in 103 patients suffering from obsessional disorder was investigated. It was compared with that of a control group of patients with non-obsessional neuroses (105 cases). Twenty patients $(19.4 \%)$ of the former group compared with eight $(7.6 \%)$ of the latter reported previous important neurological disorder. This difference is statistically significant at the $5 \%$ level.

The role of organic neurological changes in the pathogenesis of obsessional illness is discussed.

I wish to thank Professor E. W. Anderson and Professor E. Stengel for their assistance in this study. The investigation was part of a study for the degree of Doctor of Medicine in the University of Manchester.

\section{REFERENCES}

Creak, M., and Guttmann, E. (1935). J. ment. Sci., 81, 834.

Crichton-Browne, J. (1895). Lancet, $2,1$.

Ewald, G. (1924). Mschr. Psychiat., 57, 222.

Falkiewicz, T., and Rothfeld, J. (1925). Dtsch. Z. Nervenheilk, 85, 269

Fuchs, A. (1927). Arch. Psychiat. Nervenkr., 80, 586.

Gadelius, B. (1896). Om Tvängstankar. Stockholm. Quoted by G. Skoog (1959). Acta Psychiat. scand., suppl., 134.

Garmany, G. (1947). J. ment. Sci., 93, 639.

Goldstein, K. (1924). Mschr. Psychiat. Neurol., 57, 191.

Greenfield, J. G., (1958). Neuropathology. Arnold, London.

Guttmann, E. (1927). Z. ges. Neurol. Psychiat., 107, 584.

Hall, A. (1939). In A Survey of Child Psychiatry, edited by R. G. Gordon. Oxford University Press, London.

Jahrreiss, W. (1926). Arch. Psychiat. Nervenkrank., 77, 596.

Lennox, M. A. (1947). Res. Publ. Ass. nerv. ment. Dis., 26, 342.

Lewis, A. (1946). In A Textbook of Medicine, 7 th ed., edited by F. W. Price. Oxford University Press, London.

Mayer-Gross, W. and Steiner, G. (1921), Z. ges. Neurol. Psychiat., 73, 283.

Pollitt, J. D. (1958). Obsessional States. M.D. Thesis, University of London.

Scharfetter, H. (1926). Dtsch. Z. Nervenheilk., 93, 61.

Schilder, P. (1938). Amer. J. Psychiat., 94, 1397.

Skalweit, W. (1928). Mschr. Psychiat. Neurol., 67, 11.

Stern, F. (1927). Arch. Psychiat., 81, 522.

Turner, A. (1907). Epilepsy. Macmillan, London.

Wexberg, E. (1929). Z. ges. Neurol. Psychiat., 121, 236.

(1938). Amer. J. Psychiat., 94, 1415. 